\title{
Advances in Alternative and Integrative Medicine in the Treatment of Depression: A Review of the Evidence
}

\author{
Ahmad Shamabadi, MD'; Shahin Akhondzadeh, PhD $^{1 *}$ \\ ${ }^{1}$ Psychiatric Research Center, Roozbeh Psychiatric Hospital, Tehran University of Medical Sciences, Tehran, Iran
}

\begin{abstract}
Depression is a chronic and debilitating psychiatric disorder that affects 300 million people worldwide. Pharmacotherapy is one of the treatments. Due to delay in initiating treatment efficacy and the incomplete response to mono-drug therapy in onethird of patients, new approaches need to be considered. One of the ways to overcome this resistance to treatment and to enhance standard medical practice is to add complementary medicines. We aimed to document research progress from studies on integrative medicine for the treatment of depression. Review of PubMed and Scopus databases on the topic and a personal collection of the relevant publications are the sources for this study. Some of the nutraceuticals and complementary medicines in the treatment of depression will be reviewed. Supplements discussed in this review include S-adenosyl-methionine (SAMe), Crocus sativus (Saffron), carnosine, theanine, palmitoylethanolamide (PEA), tryptophan and 5-hydroxytryptophan (5-HTP), gemfibrozil, curcumin (the main active ingredient in turmeric), Hypericum perforatum (St John's wort), Lavandula angustifolia (Lavender), and Cinnamomum tamala. Despite evidence in favor of the antidepressant effect of several supplements, their efficacy and tolerability should be evaluated and validated by further high-quality studies.

Keywords: Antidepressive agents, Traditional medicine, Nutraceuticals, Herbal medicine, Complementary therapies

Cite this article as: Shamabadi A, Akhondzadeh S. Advances in Alternative and Integrative Medicine in the Treatment of Depression:

A Review of the Evidence. Arch Iran Med. Arch Iran Med. 2021;24(5):409-418. doi: 10.34172/aim.2021.59
\end{abstract}

Received: November 25, 2020, Accepted: April 27, 2021, ePublished: May 1, 2021

\section{Introduction}

\section{Definition and Importance}

Major depressive disorder (MDD), also briefly known as depression, is a chronic and debilitating psychiatric disorder and a treatable medical condition. ${ }^{1}$ According to DSM-V, MDD is characterized by one or more episodes of major depression and no life-long mania or hypomania. An episode should have at least five of the following symptoms during an at least two-week period: depressed mood, loss of pleasure, change in appetite or weight, insomnia or sleeplessness, decreased or increased irritability, decreased energy or fatigue, feelings of worthlessness or guilt, concentration disorder, and suicidal thoughts or attempted suicide. There must be at least one of the two symptoms of depressed mood and loss of pleasure to meet the criteria. ${ }^{2}$

MDD has significant potential mortality and morbidity as it results in psychosocial functioning limitations, interpersonal disturbances, substance abuse, decreased quality of life, and suicide., ${ }^{3,4}$ For this reason, MDD has been reported in the World Health Organization's (WHO's) top five causes of disease burden worldwide and is predicted to be the first cause by the year $2030 .{ }^{1}$ The disorder affects 300 million people worldwide according to the WHO. ${ }^{5}$ The lifetime risk of this disease is $15 \%$ to $18 \%$; in other words, almost one in five people experience a period of the illness in their lifetime. ${ }^{4,6}$ Alarmingly, about $2 \%-8 \%$ of adults with this disorder die by suicide. ${ }^{7}$ The estimates for financial costs associated with MDD and its treatment in the United States are high, amounting to about $\$ 97.3$ billion per annum. ${ }^{8}$

\section{The Neurobiology of MDD}

The pathogenesis of MDD is not yet fully understood, and several genes and environmental conditions appear to be involved. Anatomic and functional changes have been observed in different parts of the central nervous system. ${ }^{9}$ Impaired interactions between serotonin, norepinephrine, dopamine, glutamate, or brain-derived neurotrophic factor (BDNF) neurotransmitters with their receptors in patients' central nervous system have been suggested as mechanisms of MDD in studies. ${ }^{3}$ Significant and rapid antidepressant effects of the non-competitive N-methyl$\mathrm{D}$-aspartate (NMDA) receptor antagonist ketamine in treatment-resistant patients have been of interest in previous studies. Although monoaminergic systems (serotonin, norepinephrine, and dopamine) have been the focus of attention in the neurobiology of MDD, recent studies have focused on the role of the glutamatergic system in this disorder. ${ }^{10}$ Intercellular signaling disturbances, endocrine changes, and vascular lesions in some parts of the brain, especially lesions involving the frontostriatal pathways, are other studied mechanisms., ${ }^{9,11}$ Also, metabolism has been observed to increase in the limbic system and to decrease in the neocortex. ${ }^{12}$ 


\section{Current Therapy and Shortcomings}

Currently, available and standard treatments for depression include psychotherapy, pharmacotherapy, and electroconvulsive therapy. ${ }^{3}$ First-line medications for MDD consist of SSRIs, SNRIs, agomelatine, bupropion, mirtazapine, and vortioxetine, which should be selected based on clinical features of patients and medication characteristics. ${ }^{13-15}$ Tricyclic antidepressants and some other drugs are second-line pharmacotherapies, and MAO inhibitors and reboxetine are third-line drugs. ${ }^{13}$

Due to the significant delay in initiating treatment efficacy and the incomplete response to mono-drug therapy in approximately one-third of patients, new approaches to antidepressant therapy should be considered because resistance to treatment increases costs to the health care system and indirect costs through causes such as reduced work time and work efficiency. The symptoms of these patients continue, compromising their quality of life. ${ }^{8,15-17}$ One of the ways to overcome this resistance to treatment and to enhance standard medical practice is to add complementary drugs that are more likely to be used because of their potential efficacy, social acceptance, possible safety, and lower cost. ${ }^{17,18}$

This review aims to document data on the progress made in research on complementary medicines and adjunctive drugs for the treatment of depression. Reviewing of PubMed and Scopus databases on the topic and a personal collection of the relevant publications are the sources of this study.

\section{Medicines}

\section{S-Adenosyl-Methionine}

S-adenosyl-methionine (SAMe), which is an endogenous and intracellular amino acid metabolite, was discovered in Italy by Giulio Cantoni and has been considered for its role in the treatment of depression since the late 1970s. It is currently classified in the United States as a dietary supplement. ${ }^{19}$ SAMe is a co-substrate of biosynthetic enzymes of hormones and neurotransmitters and plays a role in the synthesis of neuronal membranes and messengers through donating a methyl group. ${ }^{20}$ A decrease in cerebrospinal fluid (CSF) SAMe concentration has been observed in patients with MDD. Concentrations in the CSF increase with increases in blood concentration due to crossing of the blood-brain barrier. ${ }^{21}$

The effectiveness of SAMe on the improvement of depressive symptoms has been evaluated in many clinical trials. $^{22}$ In a study of 189 patients, Mischoulon et al observed no significant difference between the $1600 \mathrm{mg} / \mathrm{d}$ oral SAMe and escitalopram. ${ }^{23}$ In two studies by Sarris et al, the antidepressant effect of SAMe was observed, especially in males, which may be due to the lower SAMe/ SAH (s-adenosylhomocysteine) ratio and methylation potential compared to females. ${ }^{24-26}$

In a study which included a meta-analysis, Sarris et al reported that SAMe is useful in combination therapy with antidepressants in treatment-resistant patients. ${ }^{27}$ In a review of eight articles involving 934 people, Galizia et al stated that SAMe did not differ from imipramine and escitalopram when used alone. They also noted that studies showing the antidepressant effect of SAMe in combination therapy with antidepressants lack the quality needed to make a definitive conclusion, and recommended new high-quality studies. ${ }^{19}$ In a review, Anup Sharma et al found promising but limited evidence of the antidepressant effect of monotherapy with SAMe, and they recommended further studies, as well. ${ }^{21}$

\section{Crocus sativus}

Saffron is the dried stigma of Crocus sativus L. Crocin, crocetin, picrocrocin, and safranal, which have antioxidant effects, are thought to be the principal secondary metabolites. ${ }^{28}$ Saffron increases the levels of dopamine and glutamate in the rat brain. ${ }^{29}$ Modulation of serotonergic activity and neuroprotective effects of crocin have been shown in preclinical studies. ${ }^{30,31}$ The regulatory effects of saffron on neurotransmitter pathways, the immune system, inflammation, and the hypothalamic-pituitaryadrenal axis have also been studied. ${ }^{32}$ An association has been observed between elevated levels of homocysteine and depressive disorder, and saffron is thought to decrease the levels of homocysteine. ${ }^{33}$

In a trial conducted by Akhondzadeh et al in 2004, the therapeutic effect of saffron was shown in combination therapy of mild to moderate depression without any significant side effects compared to the placebo group. ${ }^{34}$ Lopresti and colleagues reported that the combination of saffron and curcumin significantly improved depressive and anxiolytic symptoms in patients with MDD. ${ }^{35}$ In a placebo-controlled 12-week trial, Mazidi et al showed a significant effect for $50 \mathrm{mg}$ saffron on the treatment of depression and anxiety. ${ }^{36}$ In addition, significant therapeutic effects of saffron have been reported in treatment of mild to moderate postpartum depression, MDD with anxious distress, and depression associated with post-menopausal hot flashes. ${ }^{37-39}$ Two studies mentioned above, conducted by Kashani et al and Ghajar et al, showed that the effect of saffron in treatment of postpartum depression and MDD with anxious distress was not different from fluoxetine and citalopram, respectively. ${ }^{37,38}$ However, since only placebo-controlled studies are acceptable to demonstrate efficacy, further studies are recommended to evaluate efficacy.

One of the limitations of many studies of complementary medicines is a lack of examination of the elderly. In a recent study, Ahmadpanah et al demonstrated that saffron is an antidepressant in the elderly with no benefit or loss compared to sertraline. ${ }^{40}$

In a meta-analysis study, five randomized clinical trials were studied to investigate the effect of saffron on depression, which showed the positive effects of saffron on reducing the patients' symptoms. ${ }^{41}$ In another metaanalysis, including seven studies of moderate quality, the safety and comparable efficacy of saffron in combination 
with antidepressants in adults were reported..$^{42}$ In a recent systematic review and meta-analysis on this topic, the significant effect of saffron on reducing symptoms of depression, either alone or in combination therapy, was reported..$^{32}$

\section{Carnosine}

Carnosine, an endogenous dipeptide composed of $\beta$-alanine and histidine, is present in the human skeletal muscle and brain. ${ }^{43}$ The evidence suggests that carnosine is an antioxidant and anti-inflammatory agent, enhances cortisol metabolism, and inhibits telomere shortening. ${ }^{43-45}$ The protective role of carnosine ( $\beta$-alanyl histidine) against some neurodegenerative diseases such as Alzheimer's disease, its improving effects on cognitive impairment in the elderly, its potential therapeutic effect on autism spectrum disorders, and its potential to help reduce the negative symptoms of schizophrenia have been discussed in previous studies. ${ }^{43,44,46-48}$ In a recent study by Ouyang et al, the decrease in glutamate concentration in the central nervous system through upregulation of the glutamate transporter 1 has been suggested as a mechanism of the effect of carnosine in the brain. ${ }^{49}$

Previous studies have suggested the potential therapeutic effect of dietary carnosine supplements in depressive disorders. ${ }^{45}$ Tomonaga et al have reported the antidepressant effect of chicken breast extract, possibly due to carnosine, in rats. ${ }^{50} \mathrm{~A}$ more recent and clinical study by Young et al suggested the beneficial effect of chicken essence on improving the mood of healthy individuals. ${ }^{51} \mathrm{In}$ a double-blind and placebo-controlled trial by Araminia et al, L-carnosine was significantly useful in combination therapy with citalopram compared to placebo. They have also reported the rapid-onset antidepressant effect of carnosine, which requires researchers' attention in further studies. $^{52}$

\section{Theanine}

Theanine or L-theanine is an alpha-amino acid found naturally in green tea (Camellia sinensis), black tea, and some fungi. ${ }^{53,54} \mathrm{~L}$-Theanine, like caffeine and catechin, is responsible for an essential part of the health effects of tea. ${ }^{55}$ Natural synthesis of L-theanine is from L-Glutamic acid. It is thought to modulate g-aminobutyric acid (GABA), serotonin, and dopamine levels. It may also interact with kainate and NMDA receptors for glutamate..$^{53,56}$

The FDA has considered it to be generally regarded as safe (GRAS) but has recommended that its daily intake should not exceed $1200 \mathrm{mg} \cdot{ }^{54,56} \mathrm{In}$ an open-label clinical trial, Hidese et al investigated the effect of L-theanine on 20 patients with MDD. In their study, patients were given $250 \mathrm{mg}$ of L-theanine daily for eight weeks, and they observed that the depression score was significantly reduced after chronic administration of L-theanine; finally, they reported L-theanine's safety and beneficial effects on symptoms of depression. ${ }^{57}$ The study lacked a placebo group; so, further placebo-controlled studies are needed to consolidate and validate the effects.

\section{Palmitoylethanolamide}

Palmitoylethanolamide (PEA) is an endocannabinoid which is produced in plants and animals. It is produced in neurons and glial cells in humans and plays neuroprotective, analgesic, and anti-inflammatory roles. ${ }^{58}$ Previous studies have shown the role of the endocannabinoid system in depression and mood disorders. ${ }^{59}$ Glial cells and immune cells are involved in the neuro-inflammation process of psychiatric illness (such as depression) pathogenesis, and the neuroprotective and anti-inflammatory role of PEA has been shown in studies. ${ }^{59,60}$ PEA targets the peroxisome proliferator-activated receptor-alpha (PPAR- $\alpha$ ), the endocannabinoid system, the G-protein-coupled receptor 55, a non- $\mathrm{CB}_{1} / \mathrm{CB}_{2}$ cannabinoid receptor, and $\mathrm{CB}_{1} / \mathrm{CB}_{2}$ receptors. ${ }^{58,61}$

Yu et al investigated the antidepressant effect of PEA in mice. They reported that its effects on immobility reduction in the tail suspension test and the forced swimming test are comparable to fluoxetine. ${ }^{62}$ In another preclinical study conducted by Crupi et al, the antidepressant effect of the combination of PEA and luteolin was shown to decrease depression-like behavior in mice. ${ }^{63}$ In a six-week, placebocontrolled clinical trial conducted by GhazizadehHashemi et al, improvement of depressive symptoms was observed with a combination treatment of citalopram and PEA, especially in males. The drug showed rapid-onset effectiveness in their study. ${ }^{64}$ Given the evidence that the antidepressant effect of the combination of PEA and luteolin is greater than the effects of each alone, further studies are recommended to investigate the therapeutic effects of each alone and the combined effects of these two drugs in a large population with extended followup. ${ }^{60}$ Based on the available evidence, it is recommended to consider the difference between male and female responses in future studies.

\section{Tryptophan and 5-Hydroxytryptophan}

The essential plant-derived amino acid tryptophan converts to 5-hydroxytryptophan (5-HTP) and then to serotonin. ${ }^{65}$ Only $1 \%-3 \%$ of consumed tryptophan produces central serotonin through the pathway. ${ }^{66,67}$ 5-HTP, which can cross the blood-brain barrier like tryptophan, is converted to serotonin within serotonergic neurons, and to neurotransmitters within dopaminergic and noradrenergic neurons. Because of this, and also because tryptophan's entry into the brain depends on its ratio to other abundant neutral amino acids, tryptophan is not used to increase serotonin, and the use of 5-HTP to provide serotonin production is theoretically more rational. ${ }^{65,67} 5$-HTP itself is also inappropriate due to poor pharmacokinetics, short half-life, and fluctuating extracellular 5-hydroxytryptamine elevation. However, its slow-release (SR) delivery mode can be used in clinical practice by overcoming the drug limitations. ${ }^{68}$

The antidepressant effect of 5-HTP has been investigated in a limited number of old preclinical studies, 
two of which reported a dose-dependent antidepressant effect in the forced swim test (which is not an entirely appropriate assessment). In contrast, a newer study reported a depressing effect. ${ }^{69,70} 5$-HTP, both alone and in combination with an SSRI, has been studied in humans. 5-HTP was more effective in combination therapy than alone by significantly increasing extracellular 5-hydroxytryptamine in the brain, which is associated with its antidepressant effect. ${ }^{68,71}$ Previous studies do not have the quality needed for definitive conclusions for the use of 5-HTP in treatment. Therefore, currently, the Canadian Network for Mood and Anxiety Treatments (CANMAT) guideline does not recommend its use. ${ }^{72}$ Further studies are recommended to evaluate the antidepressant effect, given its safety and lack of evidence to cause any illness. ${ }^{73}$

\section{Gemfibrozil}

Gemfibrozil is a well-known and FDA-approved drug for the treatment of hypertriglyceridemia and hypercholesterolemia. Gemfibrozil is currently undergoing studies to explore its other effects. ${ }^{74}$ The antiinflammatory effect in chronic inflammatory diseases, the immunomodulatory effect by switching $\mathrm{T}$ helper 1 to $\mathrm{T}$ helper 2 cells, the antioxidant effect, and, more recently, the antidepressant effect of gemfibrozil have been of interest to researchers. ${ }^{75}$

In a study of twenty-three patients by Glueck et al, it was observed that the administration of gemfibrozil could improve symptoms of depression. They hypothesized that an increase in triglyceride might be associated with symptoms of depression. ${ }^{76}$ In a recent study on mice by $\mathrm{Ni}$ et al., the antidepressant effect after gemfibrozil administration was reported by the mechanism of change in the BDNF signaling cascade in the murine hippocampus. ${ }^{77}$ In a randomized, double-blind, and placebo-controlled clinical trial conducted by Zandifar et al, the administration of gemfibrozil adjunct to sertraline was reported to be effective in treating patients with MDD. $^{78}$

\section{Curcumin}

Curcuma longa and other Curcuma spp. plants produce curcumin and curcuminoids (demethoxycurcumin and bisdemethoxycurcumin). Curcumin is a secondary metabolite of the plant and the principal curcuminoid of turmeric. It has shown some therapeutic activities as an herbal supplement. ${ }^{79,80}$ The anti-inflammatory, antioxidant, monoaminergic, and neurotrophic activity of curcumin has been reported in several studies. ${ }^{80,81}$ In a remarkable study by Lopresti et al, it was reported that group compared to the placebo group, the curcumin had higher urinary excretion of thromboxane B2 and substance $\mathrm{P}$ and higher plasma levels of endothelin-1 and leptin, which may be related to the therapeutic effectiveness of curcumin..$^{82}$ In a pilot study by Yu et al, treatment with curcumin supplementation, in addition to alleviation of depression, decreased levels of inflammatory cytokines interleukin $1 \beta$ and tumor necrosis factor $\alpha$ and salivary cortisol concentrations and increased levels of BDNF in plasma. ${ }^{6}$

In a placebo-controlled pilot study by Bergman et al, although the relief of depressive symptoms was more rapid in the curcumin recipient group, there was no difference between the two groups at the end. ${ }^{83}$ In another clinical trial conducted by Lopresti et al, curcumin did not differ from placebo until week four, but was more effective from weeks 4 to 8 in relieving symptoms of depression, especially in patients with atypical symptoms. ${ }^{84}$ In a trial by Sanmukhani et al, no statistically significant difference in improving symptoms was observed among patients receiving fluoxetine and $1000 \mathrm{mg}$ of curcumin individually or in combination. ${ }^{85}$ Panahi and colleagues also found that an antidepressant and curcuminoidspiperine combination therapy was more effective than standard antidepressant treatment alone. ${ }^{86}$ In a study by Esmaily and colleagues, although $1000 \mathrm{mg}$ of curcumin improved anxiety, it did not statistically play a role in the treatment of depression in obese patients. ${ }^{87}$ As mentioned earlier in the saffron discussion, saffron and curcumin combinations are significantly effective in improving depressive and anxiolytic symptoms in patients with MDD. ${ }^{35}$ In a clinical trial conducted by Kanchanatawan et al on 65 patients with MDD, the antidepressant effects of curcumin were reported in combination therapy with antidepressants compared to placebo, especially in men. ${ }^{81}$ Given the evidence mentioned above, some of which is opposed to the antidepressant effect of curcumin, further high-quality studies are recommended, preferably evaluating the difference between men and women.

\section{Hypericum perforatum}

Hypericum perforatum, also called St. John's wort, is a plant of the angiosperm group that does not have US Food and Drug Administration approval despite its extensive use in traditional medicine and several studies on its antidepressant effects. ${ }^{88}$ The antidepressant, anti-inflammatory, and antibacterial activity of this plant have been of interest in studies. Its antidepressant activity is probably because of the multiplicity of bioactive compounds and through their interaction with neurotransmitters like NMDA, GABA, and serotonin receptors and monoamine oxidase inhibition..$^{88-90}$

In a placebo-controlled study conducted in 1993, the efficacy and tolerability of St. John's wort were observed in mild to moderate depression. ${ }^{91}$ In a systematic review including thirty-five studies lasting 4 to 12 weeks, the efficacy of monotherapy with St. John's wort was similar to antidepressants and higher than placebo in the treatment of mild to moderate MDD. This review considers the studies inadequate to report all adverse events. ${ }^{92}$ A more recent study examining 27 clinical trials showed similar results. Based on the CANMAT, there is level one evidence for monotherapy with St. John's wort as first-line for mild to moderate depression treatment. ${ }^{90}$ Lack of evidence 
for efficacy in severe MDD, short duration of trials, insufficient studies and preliminary investigations of side effects, and multiplicity of bioactive compounds of this plant and lack of their complete investigation are reasons to recommend further high-quality studies.

To evaluate efficacy over a more extended period, Sarris and colleagues conducted a study examining the efficacy of the plant, sertraline, and placebo treatment for up to eighteen weeks after the response to an eightweek treatment. The comparison between treatments was not significant at the end, and the surprising result was the maintenance response to the placebo. ${ }^{93}$ For surveying the last reason mentioned, in a 12-month trial, a multifractionated hypericum had better antidepressant clinical activity than conventional. ${ }^{89}$

Drug interactions should be considered as well, such as the risk of developing serotonin syndrome following coadministration with an SSRI. ${ }^{94}$

\section{Lavender}

Lavandula angustifolia (Family Lamiaceae) flower and leaf extracts are an aromatic oil called lavender. Its anti-inflammatory, anti-lipidemic, antimicrobial, antineoplastic, and analgesic and sedative roles have been reported in studies. ${ }^{95}$ 5-Hydroxytryptamine (5HT) concentration was increased in patients receiving aromatherapy (massage and inhalation). ${ }^{96}$

In a four-week clinical trial by Akhondzadeh et al, patients with mild to moderate depression were divided into three groups of recipients of imipramine alone, Lavandula tincture alone, and their combination. They found that combination therapy with imipramine and Lavandula was more effective than treatment with either imipramine or Lavandula alone. It should be noted that headaches were significantly higher in the Lavandula tincture group in their study. ${ }^{97}$ Silexan is the name of lavender oil capsules that were effective in treating mixed anxiety and depressive disorder patients with depressive symptoms in a placebo-controlled clinical trial. In that trial, Silexan recipients had significantly more eructation than placebo recipients did. One of the disadvantages of many studies on depression supplementation is the small number of patients. The number of participants in this study was 318 , which is significant in this regard. ${ }^{98}$ Another disadvantage of several trials in the treatment of depression is the lack of studying older people. In the trial by Bazrafshan and colleagues, by studying patients over the age of 60, they found that lavender had antidepressant effects in this age group as well. ${ }^{99}$ In another trial, aromatherapy massage with lavender essential oil in older women with acute coronary syndrome, not all of whom were depressed, improved anxiety and depression scores. ${ }^{100}$

\section{Cinnamomum tamala}

Cinnamomum tamala T. Nees \& Eberm (Family Lauraceae), one of the species of the genus Cinnamomum, and its compounds have been investigated in several studies for anti-inflammatory, antioxidant, anti-diabetic, lipid-lowering, antimicrobial, and wound healing effects. $^{101}$ Previous preclinical studies have suggested cinnamon and its extract to improve Alzheimer's disease, Parkinson's disease, depression, and anxiety. ${ }^{102-104}$ In a study by Upadhyay et al, the antidepressant, antistress, and anxiolytic effects of Cinnamomum tamala Nees and Eberm extract were demonstrated in mice. The antidepressant effect has been reported in this study similar to imipramine. ${ }^{105}$

The antidepressant effect of Cinnamomum tamala was evaluated in a trial designed by Ghaffari et al. In this clinical trial, Cinnamomum tamala, at a daily dose of $500 \mathrm{mg}$ in combination with sertraline, was reported to be effective in the treatment of MDD. ${ }^{106}$ Further trials by researchers in high-quality studies and larger sample sizes are recommended to investigate the antidepressant effect of Cinnamomum tamala and its mechanism.

\section{Conclusion}

Table 1 summarizes the conclusion and points. Numerous studies have been conducted on complementary and alternative therapies for depression, but some of them have had conflicting results. ${ }^{107}$ Many studies have had limitations, such as the age limit of the patients studied, short treatment periods, no follow-up of patients after treatment or its limited duration, and lack of studies addressing their effects on severe depression. Most studies do not include the elderly. However, as mentioned, there are studies on the efficacy of saffron and lavender in relieving depression in the elderly.

There is evidence in favor of similar effects of monotherapy with SAMe and some antidepressants, but the quality of the studies have not been high enough. Numerous studies have shown the antidepressant effect of saffron, either alone or in combination, and according to the CANMAT, saffron is in the third line of mild to moderate depression treatment. ${ }^{90}$ Studies have shown improvement in depressive symptoms using carnosine and PEA, mostly as an adjuvant therapy with a standard antidepressant. Research on tryptophan is incomplete, so it is currently not recommended for use. There are few preclinical and clinical studies on the effect of theanine, gemfibrozil, and Cinnamomum tamala, and those studies have reported a significant antidepressant effect; therefore, further studies are needed. Studies have not yet conclusively confirmed the antidepressant effects of curcumin; however, most recent studies have shown its antidepressant effect. One of the supplements studied extensively is Hypericum perforatum; however, previous studies have had remarkable limitations. The effectiveness of lavender has been measured in depressed and nondepressed people. It has been shown to improve the depression score.

In future studies, it is recommended that researchers pay more attention to the onset of supplements effects, such 
Table 1. Summary of Findings

\begin{tabular}{|c|c|c|c|c|}
\hline Medicines & $\begin{array}{l}\text { A Therapeutic Dose } \\
\text { Used in Depressed } \\
\text { Patients }\end{array}$ & $\begin{array}{c}\text { Significant as } \\
\text { Monotherapy Controlled } \\
\text { with Placebo }\end{array}$ & $\begin{array}{c}\text { CANMAT } \\
\text { Recommendation }\end{array}$ & Points \\
\hline S-adenosyl-methionine & 1600 mg daily 23 & Yes $^{23}$ & Adjunctive & - More effective in male ${ }^{25}$ \\
\hline Saffron & 50 mg daily ${ }^{36}$ & Yes $^{36}$ & Monotherapy Adjunctive & - Effective in the elderly ${ }^{40}$ \\
\hline Carnosine & $400 \mathrm{mg}$ b.d. ${ }^{52}$ & & & - Rapid-onset ${ }^{52}$ \\
\hline Theanine & 250 mg daily ${ }^{57}$ & & & \\
\hline Palmitoylethanolamide & $600 \mathrm{mg}$ b.d. ${ }^{64}$ & & & $\begin{array}{l}\text { - More effective in male }{ }^{64} \\
\text { - Rapid-onset }{ }^{64} \\
\text { - More effective in combination } \\
\text { with luteolin }{ }^{60}\end{array}$ \\
\hline Tryptophan and 5-HTP & & & Not recommended & \\
\hline Gemfibrozil & $300 \mathrm{mg}$ daily ${ }^{78}$ & & & \\
\hline Curcumin & 1000 mg daily ${ }^{85}$ & & & $\begin{array}{c}\text { - More effective in patients with } \\
\text { atypical symptoms } \\
\text { - Probably more effective in } \\
\text { male }^{81}\end{array}$ \\
\hline St John's wort & 900 mg daily ${ }^{92}$ & Yes $^{92}$ & Monotherapy Adjunctive & $\begin{array}{l}\text { - Risk of serotonin syndrome } \\
\text { following co-administration with } \\
\text { an SSRI }{ }^{94}\end{array}$ \\
\hline Lavender & 80 mg daily ${ }^{98}$ & Yes $^{97}$ & Adjunctive & $\begin{array}{c}\text { - Effective in the elderly }{ }^{99} \\
\text { - More effective in combination } \\
\text { with } \mathrm{ADs}^{97}\end{array}$ \\
\hline Cinnamomum tamala & 500 mg daily ${ }^{106}$ & & & \\
\hline
\end{tabular}

Not rejecting items is due to the lack of a systematic search. CANMAT Canadian Network for Mood and Anxiety Treatments. b.d. Twice a day. 5-HTP 5-hydroxytryptophan. ADs antidepressants.

as PEA and carnosine that were rapid-onset in previous studies. Differences in response to supplements between men and women should also be considered, such as in the case of PEA, curcumin, and SAMe, which have been more effective in men. Some supplements have synergistic effects in combination therapy, and some should not be prescribed with some drugs, such as PEA, which is more effective in combination with luteolin, and combination therapy with imipramine and Lavandula. In contrast, Hypericum should not be prescribed with an SSRI.

There are drugs and supplements such as gemfibrozil and theanine, whose antidepressant effects in humans have not been evaluated in high-quality studies. It is recommended that these new supplements and medicines should be studied, as well. Despite many studies, this field still needs the attention of researchers.

\section{Authors' Contribution}

SA was the principal investigator. AS wrote the manuscript.

\section{Conflict of Interest Disclosures}

The authors have no conflict of interests.

\section{Ethical Statement}

Not applicable.

\section{Funding}

This research did not receive any specific grant from funding agencies in the public, commercial, or not-for-profit sectors.

\section{References}

1. Malhi GS, Mann JJ. Depression. Lancet. 2018;392(10161):2299-312. doi: 10.1016/s01406736(18)31948-2.

2. Uher R, Payne J, Pavlova B, Perlis R. Major depressive disorder in DSM-5: Implications for clinical practice and research of changes from DSM-IV. Depress Anxiety. 2014;31:459-71. doi: 10.1002/da.22217.

3. Otte C, Gold SM, Penninx BW, Pariante CM, Etkin A, Fava M, et al. Major depressive disorder. Nat Rev Dis Primers. 2016;2:16065. doi: 10.1038/nrdp.2016.65.

4. Bromet E, Andrade LH, Hwang I, Sampson NA, Alonso J, de Girolamo G, et al. Cross-national epidemiology of DSMIV major depressive episode. BMC Med. 2011;9:90. doi: 10.1186/1741-7015-9-90.

5. Organization WH. Depression and other common mental disorders: global health estimates. Geneva: World Health Organization; 2017.

6. Yu JJ, Pei LB, Zhang Y, Wen ZY, Yang JL. Chronic Supplementation of Curcumin Enhances the Efficacy of Antidepressants in Major Depressive Disorder: A Randomized, Double-Blind, Placebo-Controlled Pilot Study. J Clin Psychopharmacol. 2015;35(4):406-10. doi: 10.1097/jcp.0000000000000352.

7. Bachmann S. Epidemiology of Suicide and the Psychiatric Perspective. Int J Environ Res Public Health. 2018;15(7):1425. doi: 10.3390/ijerph15071425.

8. Eaton WW, Martins SS, Nestadt G, Bienvenu OJ, Clarke D, Alexandre P. The burden of mental disorders. Epidemiol Rev. 2008;30:1-14. doi: 10.1093/epirev/mxn011.

9. Kim Y-K. Molecular neurobiology of major depressive disorder. Prog Neuropsychopharmacol Biol Psychiatry. 
2016;64:275-6. doi: 10.1016/j.pnpbp.2015.07.004.

10. Hashimoto K. Emerging role of glutamate in the pathophysiology of major depressive disorder. Brain Res Rev. 2009;61(2):105-23. doi: 10.1016/j.brainresrev.2009.05.005.

11. Villas Boas GR, Boerngen de Lacerda R, Paes MM, Gubert P, Almeida WLdC, Rescia VC, et al. Molecular aspects of depression: A review from neurobiology to treatment. Eur J Pharmacol. 2019;851:99-121. doi: 10.1016/j. ejphar.2019.02.024.

12. Mayberg HS, Liotti M, Brannan SK, McGinnis S, Mahurin RK, Jerabek PA, et al. Reciprocal limbic-cortical function and negative mood: converging PET findings in depression and normal sadness. Am J Psychiatry. 1999;156(5):675-82. doi: 10.1176/ajp.156.5.675.

13. Kennedy SH, Lam RW, McIntyre RS, Tourjman SV, Bhat V, Blier P, et al. Canadian Network for Mood and Anxiety Treatments (CANMAT) 2016 Clinical Guidelines for the Management of Adults with Major Depressive Disorder: Section 3. Pharmacological Treatments. Can J Psychiatry. 2016;61(9):540-60. doi: 10.1177/0706743716659417.

14. Salagre E, Grande I, Sole B, Sanchez-Moreno J, Vieta E. Vortioxetine: A new alternative for the treatment of major depressive disorder. Rev Psiquiatr Salud Ment. 2018;11(1):48-59. doi: 10.1016/j.rpsm.2017.06.006.

15. Kornstein SG, Schneider RK. Clinical features of treatmentresistant depression. J Clin Psychiatry. 2001;62 Suppl 16:18-25.

16. Nierenberg AA, DeCecco LM. Definitions of antidepressant treatment response, remission, nonresponse, partial response, and other relevant outcomes: a focus on treatment-resistant depression. J Clin Psychiatry. 2001;62 Suppl 16:5-9.

17. Fava M. Augmentation and combination strategies for complicated depression. J Clin Psychiatry. 2009;70(11):e40. doi: 10.4088/JCP.8001tx13c.

18. Kessler RC, Soukup J, Davis RB, Foster DF, Wilkey SA, Van Rompay MI, et al. The use of complementary and alternative therapies to treat anxiety and depression in the United States. Am J Psychiatry. 2001;158(2):289-94. doi: 10.1176/appi.ajp.158.2.289.

19. Galizia I, Oldani L, Macritchie K, Amari E, Dougall D, Jones $\mathrm{TN}$, et al. S-adenosyl methionine (SAMe) for depression in adults. Cochrane Database Syst Rev. 2016;10:Cd011286. doi: 10.1002/14651858.CD011286.pub2.

20. Gao J, Cahill CM, Huang X, Roffman JL, Lamon-Fava S, Fava M, et al. S-Adenosyl Methionine and Transmethylation Pathways in Neuropsychiatric Diseases Throughout Life. Neurotherapeutics. 2018;15(1):156-75. doi: 10.1007/ s13311-017-0593-0.

21. Sharma A, Gerbarg P, Bottiglieri T, Massoumi L, Carpenter LL, Lavretsky H, et al. S-Adenosylmethionine (SAMe) for Neuropsychiatric Disorders: A Clinician-Oriented Review of Research. J Clin Psychiatry. 2017;78(6):e656-e67. doi: 10.4088/JCP.16r11113.

22. De Berardis D, Orsolini L, Serroni N, Girinelli G, Iasevoli F, Tomasetti C, et al. A comprehensive review on the efficacy of S-Adenosyl-L-methionine in Major Depressive Disorder. CNS Neurol Disord Drug Targets. 2016;15(1):35-44. doi: 10 .2174/1871527314666150821103825.

23. Mischoulon D, Price LH, Carpenter LL, Tyrka AR, Papakostas GI, Baer L, et al. A double-blind, randomized, placebo-controlled clinical trial of S-adenosyl-L- methionine (SAMe) versus escitalopram in major depressive disorder. J Clin Psychiatry. 2014;75(4):370-6. doi: 10.4088/JCP.13m08591.

24. Sarris J, Papakostas GI, Vitolo O, Fava M, Mischoulon D. S-adenosyl methionine (SAMe) versus escitalopram and placebo in major depression RCT: efficacy and effects of histamine and carnitine as moderators of response. J Affect Disord. 2014;164:76-81. doi: 10.1016/j.jad.2014.03.041.

25. Sarris J, Price LH, Carpenter LL, Tyrka AR, Ng CH, Papakostas GI, et al. Is S-Adenosyl Methionine (SAMe) for Depression Only Effective in Males? A Re-Analysis of Data from a Randomized Clinical Trial. Pharmacopsychiatry. 2015;48(4-5):141-4. doi: 10.1055/s-0035-1549928.

26. King WD, Ho V, Dodds L, Perkins SL, Casson RI, Massey TE. Relationships among biomarkers of one-carbon metabolism. Mol Biol Rep. 2012;39(7):7805-12. doi: 10.1007/s11033-012-1623-y.

27. Sarris J, Murphy J, Mischoulon D, Papakostas GI, Fava M, Berk M, et al. Adjunctive nutraceuticals for depression: a systematic review and meta-analyses. Am J Psychiatry. 2016;173(6):575-87. doi: 10.1176/appi.ajp.2016.15091228.

28. Shafiee M, Arekhi S, Omranzadeh A, Sahebkar A. Saffron in the treatment of depression, anxiety and other mental disorders: Current evidence and potential mechanisms of action. J Affect Disord. 2018;227:330-7. doi: 10.1016/j. jad.2017.11.020.

29. Ettehadi H, Mojabi SN, Ranjbaran M, Shams J, Sahraei $\mathrm{H}$, Hedayati M, et al. Aqueous Extract of Saffron (Crocus sativus) Increases Brain Dopamine and Glutamate Concentrations in Rats. J Behav Brain Sci. 2013;03(03):3159. doi: 10.4236/jbbs.2013.33031.

30. Georgiadou G, Tarantilis PA, Pitsikas N. Effects of the active constituents of Crocus Sativus L., crocins, in an animal model of obsessive-compulsive disorder. Neurosci Lett. 2012;528(1):27-30. doi: 10.1016/j.neulet.2012.08.081.

31. Vahdati Hassani F, Naseri V, Razavi BM, Mehri S, Abnous $\mathrm{K}$, Hosseinzadeh $\mathrm{H}$. Antidepressant effects of crocin and its effects on transcript and protein levels of CREB, BDNF, and VGF in rat hippocampus. Daru. 2014;22(1):16. doi: 10.1186/2008-2231-22-16.

32. Marx W, Lane M, Rocks T, Ruusunen A, Loughman A, Lopresti A, et al. Effect of saffron supplementation on symptoms of depression and anxiety: a systematic review and meta-analysis. Nutr Rev. 2019;77(8):557-71. doi: 10.1093/nutrit/nuz023.

33. Jelodar G, Javid Z, Sahraian A, Jelodar S. Saffron improved depression and reduced homocysteine level in patients with major depression: A Randomized, double-blind study. Avicenna J Phytomed. 2018;8(1):43-50.

34. Akhondzadeh S, Tahmacebi-Pour N, Noorbala AA, Amini $\mathrm{H}$, Fallah-Pour H, Jamshidi AH, et al. Crocus sativus L. in the treatment of mild to moderate depression: a doubleblind, randomized and placebo-controlled trial. Phytother Res. 2005;19(2):148-51. doi: 10.1002/ptr.1647.

35. Lopresti AL, Drummond PD. Efficacy of curcumin, and a saffron/curcumin combination for the treatment of major depression: A randomised, double-blind, placebocontrolled study. J Affect Disord. 2017;207:188-96. doi: 10.1016/j.jad.2016.09.047.

36. Mazidi M, Shemshian M, Mousavi SH, Norouzy A, Kermani $\mathrm{T}$, Moghiman T, et al. A double-blind, randomized and placebo-controlled trial of Saffron (Crocus sativus L.) in the 
treatment of anxiety and depression. J Complement Integr Med. 2016;13(2):195-9. doi: 10.1515/jcim-2015-0043.

37. Kashani L, Eslatmanesh S, Saedi N, Niroomand N, Ebrahimi $M$, Hosseinian $M$, et al. Comparison of Saffron versus Fluoxetine in Treatment of Mild to Moderate Postpartum Depression: A Double-Blind, Randomized Clinical Trial. Pharmacopsychiatry. 2017;50(2):64-8. doi: 10.1055/s-0042115306.

38. Ghajar A, Neishabouri SM, Velayati N, Jahangard L, Matinnia N, Haghighi M, et al. Crocus sativus L. versus Citalopram in the Treatment of Major Depressive Disorder with Anxious Distress: A Double-Blind, Controlled Clinical Trial. Pharmacopsychiatry. 2017;50(4):152-60. doi: 10.1055/s-0042-116159.

39. Kashani L, Esalatmanesh S, Eftekhari F, Salimi S, Foroughifar T, Etesam F, et al. Efficacy of Crocus sativus (saffron) in treatment of major depressive disorder associated with post-menopausal hot flashes: a doubleblind, randomized, placebo-controlled trial. Arch Gynecol Obstet. 2018;297(3):717-24. doi: 10.1007/s00404-0184655-2.

40. Final reporton thesafetyassessment of Hypericumperforatum extract and Hypericum perforatum oil. Int J Toxicol. 2001;20 Suppl 2:31-9. doi: 10.1080/10915810160233749.

41. Hausenblas HA, Saha D, Dubyak PJ, Anton SD. Saffron (Crocus sativus L.) and major depressive disorder: a meta-analysis of randomized clinical trials. J Integr Med. 2013;11(6):377-83. doi: 10.3736/jintegrmed2013056.

42. Yang X, Chen X, Fu Y, Luo Q, Du L, Qiu H, et al. Comparative efficacy and safety of Crocus sativus L. for treating mild to moderate major depressive disorder in adults: a metaanalysis of randomized controlled trials. Neuropsychiatr Dis Treat. 2018;14:1297-305. doi: 10.2147/ndt.S157550.

43. Hipkiss AR. Carnosine, a protective, anti-ageing peptide? Int J Biochem Cell Biol. 1998;30(8):863-8. doi: 10.1016/ s1357-2725(98)00060-0.

44. Kawahara M, Tanaka KI, Kato-Negishi M. Zinc, Carnosine, and Neurodegenerative Diseases. Nutrients. 2018;10(2):147. doi: 10.3390/nu10020147.

45. Hipkiss AR. Possible benefit of dietary carnosine towards depressive disorders. Aging Dis. 2015;6(5):300-3. doi: 10.14336/ad.2014.1211.

46. Rokicki J, Li L, Imabayashi E, Kaneko J, Hisatsune T, Matsuda H. Daily carnosine and anserine supplementation alters verbal episodic memory and resting state network connectivity in healthy elderly adults. Front Aging Neurosci. 2015;7:219. doi: 10.3389/fnagi.2015.00219.

47. Rossignol DA. Novel and emerging treatments for autism spectrum disorders: a systematic review. Ann Clin Psychiatry. 2009;21(4):213-36.

48. Ghajar A, Khoaie-Ardakani MR, Shahmoradi Z, Alavi AR, Afarideh M, Shalbafan MR, et al. L-carnosine as an add-on to risperidone for treatment of negative symptoms in patients with stable schizophrenia: A double-blind, randomized placebo-controlled trial. Psychiatry Res. 2018;262:94-101. doi: 10.1016/j.psychres.2018.02.012.

49. Ouyang L, Tian Y, Bao Y, Xu H, Cheng J, Wang B, et al. Carnosine decreased neuronal cell death through targeting glutamate system and astrocyte mitochondrial bioenergetics in cultured neuron/astrocyte exposed to OGD/recovery. Brain Res Bull. 2016;124:76-84. doi: 10.1016/j.brainresbull.2016.03.019.
50. Tomonaga S, Yamane H, Onitsuka E, Yamada S, Sato M, Takahata Y, et al. Carnosine-induced antidepressant-like activity in rats. Pharmacol Biochem Behav. 2008;89(4):62732. doi: 10.1016/j.pbb.2008.02.021.

51. Young H, Benton D, Carter N. The effect of chicken extract on mood, cognition and heart rate variability. Nutrients. 2015;7(2):887-904. doi: 10.3390/nu7020887.

52. Araminia B, Shalbafan M, Mortezaei A, Shirazi E, Ghaffari S, Sahebolzamani E, et al. L-Carnosine combination therapy for major depressive disorder: A randomized, double-blind, placebo-controlled trial. J Affect Disord. 2020;267:131-6. doi: 10.1016/j.jad.2020.02.020.

53. Turkozu D, Sanlier N. L-theanine, unique amino acid of tea, and its metabolism, health effects, and safety. Crit Rev Food Sci Nutr. 2017;57(8):1681-7. doi: 10.1080/10408398.2015.1016141.

54. Vuong QV, Bowyer MC, Roach PD. L-Theanine: properties, synthesis and isolation from tea. J Sci Food Agric. 2011;91(11):1931-9. doi: 10.1002/jsfa.4373.

55. Pinto M. Tea: A new perspective on health benefits. Food Research International. 2013;53:558-67. doi: 10.1016/j. foodres.2013.01.038.

56. Mu W, Zhang T, Jiang B. An overview of biological production of L-theanine. Biotechnol Adv. 2015;33(34):335-42. doi: 10.1016/j.biotechadv.2015.04.004.

57. Hidese S, Ota M, Wakabayashi C, Noda T, Ozawa H, Okubo T, et al. Effects of chronic l-theanine administration in patients with major depressive disorder: an open-label study. Acta Neuropsychiatr. 2017;29(2):72-9. doi: 10.1017/ neu.2016.33.

58. Mattace Raso G, Russo R, Calignano A, Meli R. Palmitoylethanolamide in CNS health and disease. Pharmacol Res. 2014;86:32-41. doi: 10.1016/j. phrs.2014.05.006.

59. Coppola M, Mondola R. Is there a role for palmitoylethanolamide in the treatment of depression? Med Hypotheses. 2014;82(5):507-11. doi: 10.1016/j. mehy.2013.12.016.

60. Cordaro M, Cuzzocrea S, Crupi R. An update of palmitoylethanolamide and luteolin effects in preclinical and clinical Studies of neuroinflammatory events. Antioxidants (Basel). 2020;9(3):216. doi: 10.3390/antiox9030216.

61. De Gregorio D, Manchia M, Carpiniello B, Valtorta F, Nobile M, Gobbi G, et al. Role of palmitoylethanolamide (PEA) in depression: Translational evidence: Special Section on "Translational and Neuroscience Studies in Affective Disorders". Section Editor, Maria Nobile MD, $\mathrm{PhD}$. This Section of JAD focuses on the relevance of translational and neuroscience studies in providing a better understanding of the neural basis of affective disorders. The main aim is to briefly summaries relevant research findings in clinical neuroscience with particular regards to specific innovative topics in mood and anxiety disorders. J Affect Disord. 2019;255:S0165-0327(18)31599-4. doi: 10.1016/j. jad.2018.10.117.

62. Yu HL, Deng XQ, Li YJ, Li YC, Quan ZS, Sun XY. N-palmitoylethanolamide, an endocannabinoid, exhibits antidepressant effects in the forced swim test and the tail suspension test in mice. Pharmacol Rep. 2011;63(3):834-9. doi: 10.1016/s1734-1140(11)70596-5.

63. Crupi R, Paterniti I, Ahmad A, Campolo M, Esposito E, Cuzzocrea S. Effects of palmitoylethanolamide and 
luteolin in an animal model of anxiety/depression. CNS Neurol Disord Drug Targets. 2013;12(7):989-1001. doi: $10.2174 / 18715273113129990084$.

64. Ghazizadeh-Hashemi M, Ghajar A, Shalbafan MR, Ghazizadeh-Hashemi F, Afarideh M, Malekpour F, et al. Palmitoylethanolamide as adjunctive therapy in major depressive disorder: A double-blind, randomized and placebo-controlled trial. J Affect Disord. 2018;232:127-33. doi: 10.1016/j.jad.2018.02.057.

65. Friedman M. Analysis, nutrition, and health benefits of tryptophan. Int J Tryptophan Res. 2018;11:1178646918802282. doi: $10.1177 / 1178646918802282$.

66. Sirek A, Sirek OV. Serotonin: a review. Can Med Assoc J. 1970;102(8):846-9.

67. Shaw KA, Turner J, Del Mar C. Tryptophan and 5-hydroxytryptophan for depression. Cochrane Database Syst Rev. 2002;(1):CD003198. doi: 10.1002/14651858. CD003198.

68. Jacobsen JPR, Krystal AD, Krishnan KRR, Caron MG. Adjunctive 5-hydroxytryptophan slow-release for treatment-resistant depression: clinical and preclinical rationale. Trends Pharmacol Sci. 2016;37(11):933-44. doi: 10.1016/j.tips.2016.09.001.

69. Dome P, Tombor L, Lazary J, Gonda X, Rihmer Z. Natural health products, dietary minerals and over-the-counter medications as add-on therapies to antidepressants in the treatment of major depressive disorder: a review. Brain Res Bull. 2019;146:51-78. doi: 10.1016/j. brainresbull.2018.12.015.

70. Hansen F, de Oliveira DL, Amaral FU, Guedes FS, Schneider TJ, Tumelero AC, et al. Effects of chronic administration of tryptophan with or without concomitant fluoxetine in depression-related and anxiety-like behaviors on adult rat. Neurosci Lett. 2011;499(2):59-63. doi: 10.1016/j. neulet.2011.05.032.

71. Lowe SL, Yeo KP, Teng L, Soon DK, Pan A, Wise SD, et al. L-5-Hydroxytryptophan augments the neuroendocrine response to a SSRI. Psychoneuroendocrinology. 2006;31(4):473-84. doi: 10.1016/j.psyneuen.2005.11.005.

72. Ravindran AV, Balneaves LG, Faulkner G, Ortiz A, McIntosh D, Morehouse RL, et al. Canadian Network for Mood and Anxiety Treatments (CANMAT) 2016 Clinical Guidelines for the Management of Adults with Major Depressive Disorder: Section 5. Complementary and Alternative Medicine Treatments. Can J Psychiatry. 2016;61(9):576-87. doi: 10.1177/0706743716660290.

73. Das YT, Bagchi M, Bagchi D, Preuss HG. Safety of 5-hydroxy-1-tryptophan. Toxicol Lett. 2004;150(1):111-22. doi: 10.1016/j.toxlet.2003.12.070.

74. Quintanilla Rodriguez BS, Correa R. Gemfibrozil. StatPearls. Treasure Island (FL): StatPearls Publishing LLC.; 2020.

75. Roy A, Pahan K. Gemfibrozil, stretching arms beyond lipid lowering. Immunopharmacol Immunotoxicol. 2009;31(3):339-51. doi: 10.1080/08923970902785253.

76. Glueck CJ, Tieger M, Kunkel R, Tracy T, Speirs J, Streicher $\mathrm{P}$, et al. Improvement in symptoms of depression and in an index of life stressors accompany treatment of severe hypertriglyceridemia. Biol Psychiatry. 1993;34(4):240-52. doi: 10.1016/0006-3223(93)90078-r.

77. Ni YF, Wang H, Gu QY, Wang FY, Wang YJ, Wang JL, et al.
Gemfibrozil has antidepressant effects in mice: Involvement of the hippocampal brain-derived neurotrophic factor system. J Psychopharmacol. 2018;32(4):469-81. doi: 10.1177/0269881118762072.

78. Zandifar A, Badrfam R, Shamabadi A, Jalilevand S, Pourmirbabaei S, Torkamand F, et al. Efficacy of gemfibrozil as an adjunct to sertraline in major depressive disorder, a double-blind, randomized, and placebo-controlled clinical trial. Iranian Journal of Psychiatry. 2021;16(1):52-9.

79. Lestari ML, Indrayanto G. Curcumin. Profiles drug subst excip relat methodol. 2014;39:113-204. doi: 10.1016/b9780-12-800173-8.00003-9.

80. Kaufmann FN, Gazal M, Bastos CR, Kaster MP, Ghisleni G. Curcumin in depressive disorders: an overview of potential mechanisms, preclinical and clinical findings. Eur J Pharmacol. 2016;784:192-8. doi: 10.1016/j. ejphar.2016.05.026.

81. Kanchanatawan B, Tangwongchai S, Sughondhabhirom A, Suppapitiporn S, Hemrunrojn S, Carvalho AF, et al. Add-on treatment with curcumin has antidepressive effects in Thai patients with major depression: results of a randomized double-blind placebo-controlled study. Neurotox Res. 2018;33(3):621-33. doi: 10.1007/s12640-017-9860-4.

82. Lopresti AL, Maes M, Meddens MJ, Maker GL, Arnoldussen E, Drummond PD. Curcumin and major depression: a randomised, double-blind, placebo-controlled trial investigating the potential of peripheral biomarkers to predict treatment response and antidepressant mechanisms of change. Eur Neuropsychopharmacol. 2015;25(1):38-50. doi: 10.1016/j.euroneuro.2014.11.015.

83. Bergman J, Miodownik C, Bersudsky Y, Sokolik S, Lerner PP, Kreinin A, et al. Curcumin as an add-on to antidepressive treatment: a randomized, double-blind, placebo-controlled, pilot clinical study. Clin Neuropharmacol. 2013;36(3):73-7. doi: 10.1097/WNF.0b013e31828ef969.

84. Lopresti AL, Maes M, Maker GL, Hood SD, Drummond PD. Curcumin for the treatment of major depression: a randomised, double-blind, placebo controlled study. J Affect Disord. 2014;167:368-75. doi: 10.1016/j.jad.2014.06.001.

85. Sanmukhani J, Satodia V, Trivedi J, Patel T, Tiwari D, Panchal $\mathrm{B}$, et al. Efficacy and safety of curcumin in major depressive disorder: a randomized controlled trial. Phytother Res. 2014;28(4):579-85. doi: 10.1002/ptr.5025.

86. Panahi Y, Badeli R, Karami GR, Sahebkar A. Investigation of the efficacy of adjunctive therapy with bioavailabilityboosted curcuminoids in major depressive disorder. Phytother Res. 2015;29(1):17-21. doi: 10.1002/ptr.5211.

87. Esmaily H, Sahebkar A, Iranshahi M, Ganjali S, Mohammadi A, Ferns G, et al. An investigation of the effects of curcumin on anxiety and depression in obese individuals: A randomized controlled trial. Chin J Integr Med. 2015;21(5):332-8. doi: 10.1007/s11655-015-2160-z.

88. Furhad S, Bokhari AA. Herbal Supplements. StatPearls. Treasure Island (FL): StatPearls Publishing LLC.; 2020.

89. Di Pierro F, Risso P, Settembre R. Role in depression of a multi-fractionated versus a conventional Hypericum perforatum extract. Panminerva Med. 2018;60(4):156-60. doi: 10.23736/s0031-0808.18.03518-8.

90. Ravindran AV, Balneaves LG, Faulkner G, Ortiz A, McIntosh D, Morehouse RL, et al. Canadian network for mood and anxiety treatments (CANMAT) 2016 clinical guidelines for the management of adults with major depressive disorder: 
section 5. Complementary and Alternative Medicine Treatments. Can J Psychiatry. 2016;61(9):576-87. doi: 10.1177/0706743716660290.

91. Schmidt U, Sommer H. St. John's wort extract in the ambulatory therapy of depression. Attention and reaction ability are preserved [German]. Fortschr Med. 1993;111(19):339-42.

92. Apaydin EA, Maher AR, Shanman R, Booth MS, Miles JN, Sorbero ME, et al. A systematic review of St. John's wort for major depressive disorder. Syst Rev. 2016;5(1):148. doi: 10.1186/s13643-016-0325-2.

93. Sarris J, Fava M, Schweitzer I, Mischoulon D. St John's wort (Hypericum perforatum) versus sertraline and placebo in major depressive disorder: continuation data from a 26week RCT. Pharmacopsychiatry. 2012;45(7):275-8. doi: 10.1055/s-0032-1306348.

94. Hu Z, Yang X, Ho PC, Chan SY, Heng PW, Chan E, et al. Herb-drug interactions: a literature review. Drugs. 2005;65(9):1239-82. doi: 10.2165/00003495-20056509000005 .

95. Lavender. LiverTox: Clinical and Research Information on Drug-Induced Liver Injury. Bethesda (MD): National Institute of Diabetes and Digestive and Kidney Diseases; 2012.

96. Xiong M, Li Y, Tang P, Zhang Y, Cao M, Ni J, et al. Effectiveness of aromatherapy massage and inhalation on symptoms of depression in chinese community-dwelling older adults. J Altern Complement Med. 2018;24(7):717-24. doi: 10.1089/acm.2017.0320.

97. Akhondzadeh S, Kashani L, Fotouhi A, Jarvandi S, Mobaseri M, Moin M, et al. Comparison of Lavandula angustifolia Mill. tincture and imipramine in the treatment of mild to moderate depression: a double-blind, randomized trial. Prog Neuropsychopharmacol Biol Psychiatry. 2003;27(1):123-7. doi: 10.1016/s0278-5846(02)00342-1.

98. Kasper S, Volz HP, Dienel A, Schläfke S. Efficacy of Silexan in mixed anxiety-depression--A randomized, placebo-controlled trial. Eur Neuropsychopharmacol. 2016;26(2):331-40. doi: 10.1016/j.euroneuro.2015.12.002.

99. Bazrafshan M-R, Jokar M, Shokrpour N, Delam H. The effect of lavender herbal tea on the anxiety and depression of the elderly: a randomized clinical trial. Complement Ther Med. 2020;50:102393. doi: 10.1016/j.ctim.2020.102393.

100. Bahrami T, Rejeh N, Heravi-Karimooi M, Vaismoradi M, Tadrisi SD, Sieloff C. Effect of aromatherapy massage on anxiety, depression, and physiologic parameters in older patients with the acute coronary syndrome: A randomized clinical trial. Int J Nurs Pract. 2017;23(6). doi: 10.1111/ ijn. 12601 .

101. Upadhyay RK, Ahmad S. Ethno-medicinal plants and their pharmaceutical potential. J Pharmacy Res. 2,5(4):21622173.

102. Frydman-Marom A, Levin A, Farfara D, Benromano T, Scherzer-Attali R, Peled S, et al. Orally administrated cinnamon extract reduces beta-amyloid oligomerization and corrects cognitive impairment in Alzheimer's disease animal models. PLoS One. 2011;6(1):e16564. doi: 10.1371/ journal.pone.0016564.

103. Khasnavis S, Pahan K. Cinnamon treatment upregulates neuroprotective proteins Parkin and DJ-1 and protects dopaminergic neurons in a mouse model of Parkinson's disease. J Neuroimmune Pharmacol. 2014;9(4):569-81. doi: 10.1007/s11481-014-9552-2.

104. Sohrabi R, Pazgoohan N, Seresht HR, Amin B. Repeated systemic administration of the cinnamon essential oil possesses anti-anxiety and anti-depressant activities in mice. Iran J Basic Med Sci. 2017;20(6):708-14. doi: 10.22038/ijbms.2017.8841.

105. Upadhyay G, Khoshla S, Kosuru R, Singh S. Anxiolytic, antidepressant, and antistress activities of the aqueous extract of Cinnamomum tamala Nees and Eberm in rats. Indian J Pharmacol. 2016;48(5):555-61. doi: 10.4103/02537613.190752 .

106. Ghaffari S, Ghobadi A, Jamshidi AH, Mortazavi SH, Naderi $\mathrm{S}$, Aqamolaei A, et al. Cinnamomum tamala as an adjuvant therapy in the treatment of major depressive disorder: A double-blind, randomized, placebo-controlled clinical trial with placebo control. Adv Integr Med. 2019. doi: 10.1016/j. aimed.2019.12.002. 